\title{
Albendazole induces oxidative stress and DNA damage in the parasitic protozoan Giardia duodenalis
}

\author{
Rodrigo Martínez-Espinosa ${ }^{1}$, Raúl Argüello-García ${ }^{1}$, Emma Saavedra ${ }^{2}$ and \\ Guadalupe Ortega-Pierres ${ }^{1 *}$
}

${ }^{1}$ Departamento de Genética y Biología Molecular, Centro de Investigación y de Estudios Avanzados del Instituto Politécnico Nacional, México City, Mexico, ${ }^{2}$ Department of Biochemistry, Instituto Nacional de Cardiología Ignacio Chávez, México City, Mexico

OPEN ACCESS

Edited by:

Anjan Debnath,

University of California, San Diego,

USA

Reviewed by:

Nigel Yarlett,

Pace University, USA

Tomoyoshi Nozaki,

National Institute of Infectious

Diseases, Japan

*Correspondence:

Guadalupe Ortega-Pierres, Departamento de Genética y Biología Molecular, Centro de Investigación y de Estudios Avanzados del Instituto Politécnico Nacional, Avenue Instituto Politécnico Nacional 2508, San Pedro Zacatenco, 07360 México City,

Mexico

gortega@cinvestav.mx

Specialty section:

This article was submitted to Antimicrobials, Resistance

and Chemotherapy,

a section of the journa

Frontiers in Microbiology

Received: 13 March 2015

Accepted: 22 July 2015

Published: 06 August 2015

Citation:

Martínez-Espinosa $R$,

Argüello-García R, Saavedra E

and Ortega-Pierres G (2015)

Albendazole induces oxidative stress and DNA damage in the parasitic

protozoan Giardia duodenalis.

Front. Microbiol. 6:800

doi: 10.3389/fmicb.2015.00800
The control of Giardia duodenalis infections is carried out mainly by drugs, among these albendazole (ABZ) is commonly used. Although the cytotoxic effect of ABZ usually involves binding to $\beta$-tubulin, it has been suggested that oxidative stress may also play a role in its parasiticidal mechanism. In this work the effect of ABZ in Giardia clones that are susceptible or resistant to different concentrations $(1.35,8$, and $250 \mu \mathrm{M})$ of this drug was analyzed. Reactive oxygen species (ROS) were induced by ABZ in susceptible clones and this was associated with a decrease in growth that was alleviated by cysteine supplementation. Remarkably, ABZ-resistant clones exhibited partial cross-resistance to $\mathrm{H}_{2} \mathrm{O}_{2}$, whereas a Giardia $\mathrm{H}_{2} \mathrm{O}_{2}$-resistant strain can grow in the presence of ABZ. Lipid oxidation and protein carbonylation in ABZ-treated parasites did not show significant differences as compared to untreated parasites; however, ABZ induced the formation of $8 \mathrm{OHdG}$ adducts and DNA degradation, indicating nucleic acid oxidative damage. This was supported by observations of histone H2AX phosphorylation in ABZ-susceptible trophozoites treated with $250 \mu \mathrm{M}$ ABZ. Flow cytometry analysis showed that ABZ partially arrested cell cycle in drug-susceptible clones at G2/M phase at the expense of cells in G1 phase. Also, ABZ treatment resulted in phosphatidylserine exposure on the parasite surface, an event related to apoptosis. All together these data suggest that ROS induced by ABZ affect Giardia genetic material through oxidative stress mechanisms and subsequent induction of apoptotic-like events.

Keywords: Giardia duodenalis, albendazole, oxidative stress, DNA damage, apoptosis

\section{Introduction}

Giardia duodenalis is an intestinal parasitic protozoan that causes the infection known as giardiasis which affects about 280 million people around the world; 500,000 new cases are reported each year (Lane and Lloyd, 2002; Plutzer et al., 2010). This parasite is orally transmitted by the ingestion of infective cysts. Once in the host's stomach excystation occurs and trophozoites emerge. At the duodenum the parasites replicate and colonize this portion of the intestine. Subsequently trophozoites are transported by peristalsis to the jejunum and the ileum where encystation takes place and mature cysts are expelled in the stool (Ankarklev et al., 2010; Watkins and Eckmann, 2014). The infection can be asymptomatic or present several clinical manifestations ranging from mild to severe symptoms that include diarrhea, steatorrhea, post-prandial epigastric pain, anorexia, 
bloating, and flatulence (Rossignol et al., 2012; Nash, 2013). Some infected patients may develop a chronic infection with recurrent diarrhea, steatorrhea, malabsorption, weight loss, and poor growth in children (Plutzer et al., 2010; Watkins and Eckmann, 2014).

The control of this infection is mainly carried out by treatment with chemotherapeutic agents. Among the drugs used are components that belong to 5-nitroimidazoles (e.g., metronidazole) and benzimidazoles (e.g., albendazole) derivatives. Other drugs prescribed against Giardia include nitazoxanide, furazolidone, paromomycin, and quinacrine (Tejman-Yarden and Eckmann, 2011; Watkins and Eckmann, 2014). Among these drugs albendazole (ABZ) is given in massive chemotherapy interventions against helminths based on its relative safety, high efficacy, broad spectrum against helminths, and low cost (Rossignol, 2010; Watkins and Eckmann, 2014). Further ABZ has been used against Giardia, particularly when metronidazole refractory cases occur (Lemée et al., 2000; Solaymani-Mohammadi et al., 2010). The side effects of this drug are rare but in some cases anorexia, constipation and neutropenia have been reported (Dayan, 2003). The use of ABZ is contraindicated during pregnancy due to possible teratogenic effects, although such effects have not been entirely confirmed (Gardner and Hill, 2001; Dayan, 2003).

In pharmacokinetic studies it has been determined that after its absorption, $\mathrm{ABZ}$ is oxidized to its metabolites, sulphoxide and sulphone, by cytochrome P450 and/or by flavin-dependent oxidases (Dayan, 2003). The production of these metabolites has been reported in Giardia after ABZ exposure (Oxberry et al., 2000; Argüello-García et al., 2015). It has also been reported that in helminths and fungi ABZ selectively binds to four $\beta$-tubulin sites, preventing its polymerization and affecting microtubule stability which in turn inhibits mobility and transport of molecules within the microorganism (Robinson et al., 2004; Diawara et al., 2013; Watkins and Eckmann, 2014). In helminths, ABZ-resistant parasites harbor hot-spot mutations in $\beta$-tubulin encoding different amino acids, particularly at glutamate 198 and phenylalanine 200 (Rossignol, 2010; Diawara et al., 2013; Hansen et al., 2013). In Giardia, it has been established that hot-spot amino acid mutations in $\beta$-tubulin are absent (Upcroft et al., 1996; Argüello-García et al., 2009) suggesting that the induction of ABZ-resistant phenotypes involves different mechanisms.

Regarding ABZ resistance in Giardia, it has been reported that resistant trophozoites display morphological changes, particularly in the median body, despite the conserved amino acid residues at positions 198 and 200 in $\beta$-tubulin (Chavez et al., 1992; Upcroft et al., 1996; Argüello-García et al., 2009). On the other hand, chromosomal rearrangements have been documented in ABZ-treated parasites, although there is no evidence of a gene or group of genes that may be affected during $A B Z$ resistance in this parasite (Upcroft and Upcroft, 2001). Previous studies by our group suggest that diverse metabolic mechanisms may be involved in the ABZ resistance in Giardia that could include components of antioxidant and energy metabolism as well as cytoskeletal changes in the parasite (Paz-Maldonado et al., 2013).

In this context, recent reports have suggested a direct relationship between the use of $\mathrm{ABZ}$ and oxidative stress. In a report in which $\mathrm{ABZ}$ was administered to rats in various doses and times, oxidative stress was elicited particularly in hepatocytes (Locatelli et al., 2004). Other studies have also shown the ability of $\mathrm{ABZ}$ to induce oxidative stress in sheep liver (Dimitrijević et al., 2012), and ABZ consumption may be correlated with liver damage in humans (Nandi and Sarkar, 2013). In Dicrocoelium dendriticum, a fluke of veterinary and human health importance, an increase in antioxidant enzyme activity after ABZ exposure was identified (Bártíková et al., 2010). However, no reports on oxidative damage due to $\mathrm{ABZ}$ in other parasites are available.

To determine in more detail the mode of action of $\mathrm{ABZ}$ in Giardia, in this work we have assessed the induction of oxidative stress by $\mathrm{ABZ}$ in $G$. duodenalis trophozoites by monitoring reactive oxygen species (ROS) formation. Results identified ABZinduced oxidative stress in this protozoan. Oxidative damage to the parasite's DNA is associated with cell cycle arrest and apoptosis. The consequences of this stress and its possible relationship to $\mathrm{ABZ}$ resistance in Giardia are discussed.

\section{Materials and Methods}

\section{Trophozoite Cultures, Growth of ABZ-Resistant Clones and Obtention of $\mathrm{H}_{2} \mathrm{O}_{2}$-Resistant Trophozoites}

Giardia duodenalis trophozoites of the WB strain (ATCC\#30957) and ABZ-resistant clones were maintained in TYI-S-33 medium supplemented with 10\% adult bovine serum (HyClone) and antibiotic/antimycotic solution (Thermo, USA) at $37^{\circ} \mathrm{C}$ (Keister, 1983 ) in $4.5 \mathrm{~mL}$ screw-capped vials. ABZ-resistant trophozoites were selected by continuous subculture under increasing sublethal concentrations of ABZ (Sigma cat. A-4673). When parasites were adapted to each increase of drug concentration, cultures were cloned by limiting dilution using the corresponding ABZ concentration (Paz-Maldonado et al., 2013). Trophozoites were sub-cultured twice a week under the continuous presence of drug (for ABZ-resistant clones) and for the ABZ-sensitive clones only in the presence of the vehicle $(\mathrm{N}, \mathrm{N}$-dimethylformamide; DMF, Sigma). To obtain the $\mathrm{H}_{2} \mathrm{O}_{2}$-resistant parasites (ROX), trophozoites were selected by continuous subculture under increasing sub-lethal concentrations of $\mathrm{H}_{2} \mathrm{O}_{2}$ (Sigma, USA). Vials containing trophozoites were refilled to three-quarter capacity and $\mathrm{H}_{2} \mathrm{O}_{2}$-resistant parasites were cultured as described above for ABZ-resistant Giardia. Stock solutions (0.01-25 mM) of ABZ in DMF or DMF alone were used in all assays. Oxidative stress was induced by exposing the parasites to $100 \mu \mathrm{M} \mathrm{H}_{2} \mathrm{O}_{2}$ and these cultures were used as positive controls (Raj et al., 2013).

\section{Determination of Trophozoite Growth}

Trophozoite growth was assessed by the fluorescent tracer SYTOX Green according to the manufacturer's instructions (Invitrogen, USA). Briefly, trophozoites were washed three times in phosphate buffered saline (PBS) then suspended in lysis buffer (6\% SDS, $10 \mathrm{mM}$ HEPES) using a Vortex shaker for $10 \mathrm{~s}$. A stock solution of SYTOX Green $(5 \mathrm{mM})$ was added in a 1:5 $\mathrm{v} / \mathrm{v}$ ratio and incubated for $10 \mathrm{~min}$ in the dark. The standard 
growth curve was obtained using variable numbers of lysed trophozoites and absorbance values of each sample from nontreated and treated trophozoites were determined in 96-well, black-bottomed microtiter plates using a FACSCalibur reader fitted with 504/525 nm excitation/emission filters (Gerphagnon et al., 2013). Negative control absorbance values were obtained from wells with no cells.

\section{Detection of Reactive Oxigen Species (ROS) in Trophozoites Incubated with $\mathrm{ABZ}$ or $\mathrm{H}_{2} \mathrm{O}_{2}$}

Albendazole-sensitive trophozoites were incubated with $\mathrm{ABZ}$ $(1.35,8$, and $250 \mu \mathrm{M})$, Dimethylformamide (DMF referred as vehicle) or $\mathrm{H}_{2} \mathrm{O}_{2}(100 \mu \mathrm{M})$ as control for oxidative stress, for $16 \mathrm{~h}$ at $37^{\circ} \mathrm{C}$. ROS formation was assessed by Image-IT LIVE Green Reactive Oxygen Species Detection Kit ${ }^{\mathrm{TM}}$ according to manufacturer's instructions (Life Technologies, USA). After incubation, trophozoites were washed in PBS and suspended in $25 \mu \mathrm{M}$ 6-carboxy- $2^{\prime}, 7^{\prime}$-dichlorodihydrofluorescein diacetate (carboxy- H2DCFDA) at $37^{\circ} \mathrm{C}$ for $30 \mathrm{~min}$. Then Hoechst 33342 was added at a final concentration of $1 \mu \mathrm{M}$ for $5 \mathrm{~min}$. Cell fluorescence signals were detected at the end of the incubation period in a Beckman FACSCalibur Flow Cytometer or in an optical microscope using the BD FACSComp software.

\section{Determination of Cross-Resistance to ABZ and $\mathrm{H}_{2} \mathrm{O}_{2}$ and Protection by Cysteine}

The cross resistance between $\mathrm{ABZ}$ and $\mathrm{H}_{2} \mathrm{O}_{2}$ was evaluated using the $\mathrm{ABZ}$-resistant and $\mathrm{H}_{2} \mathrm{O}_{2}$-resistant clones mentioned above. The ABZ-resistant clones (R1.35, R8, R250) were exposed to 0, $25,50,75$, and $100 \mu \mathrm{M} \mathrm{H}_{2} \mathrm{O}_{2}$ for $24 \mathrm{~h}$ at $37^{\circ} \mathrm{C}$. Cell number was determined by SYTOX Green. Resistance to ABZ was determined in $\operatorname{ROX}\left(\mathrm{H}_{2} \mathrm{O}_{2}\right.$-resistant) parasites which were exposed to 0.05 , $0.1,0.2,0.4$, and $0.8 \mu \mathrm{M}$ of $\mathrm{ABZ}$ for $24 \mathrm{~h}$ at $37^{\circ} \mathrm{C}$. In control cultures, $\mathrm{ABZ}$ or $\mathrm{H}_{2} \mathrm{O}_{2}$ were not added. Cell number was also determined using SYTOX Green. For cysteine protection assays, ABZ-sensitive trophozoites were grown in TYI-S-33 medium supplemented with different concentrations of cysteine $(0.5,1,2$, or $4 \mathrm{mM})$. Then, trophozoites were incubated in the presence of $0.2 \mu \mathrm{M}$ ABZ for $48 \mathrm{~h}$ at $37^{\circ} \mathrm{C}$. Cell growth was determined by SYTOX Green as indicated above.

\section{Detection of Protein Carbonylation and Lipid Peroxidation}

Albendazole-sensitive trophozoites were incubated with DMF, $\operatorname{ABZ}(1.35,8$, and $250 \mu \mathrm{M})$ or $\mathrm{H}_{2} \mathrm{O}_{2}(100 \mu \mathrm{M})$ for $24 \mathrm{~h}$ at $37^{\circ} \mathrm{C}$. Protein carbonylation was determined using a commercial kit (Protein Carbonyl Assay, Cayman Chemical, USA). Trophozoites were washed with PBS, suspended in lysis solution $(50 \mathrm{mM}$ MES, $1 \mathrm{mM}$ EDTA at $\mathrm{pH}$ 7.4) and lysed by three cycles of freezing-thawing followed by centrifugation at 10,000 $\mathrm{x} g$ for $10 \mathrm{~min}$. Subsequently the protein was derivatized with dinitrophenylhydrazine (DNPH) for $60 \mathrm{~min}$ in the dark, the reaction was stopped with $20 \%$ trichloroacetic acid and samples were centrifuged at $10,000 \times g$ for $10 \mathrm{~min}$. Then the samples were washed three times with ethanol/ethyl acetate solution. Finally, the proteins were suspended in guanidine hydrochloride and the absorbance was determined at $450 \mathrm{~nm}$ (Krisko and Radman,
2010). The concentration of protein in the soluble fraction was determined by absorbance at $280 \mathrm{~nm}$.

For lipid peroxidation determination, after incubation with compounds or vehicle a solution of 1-methyl-2-phenylindole in a mixture of acetonitrile/methanol (3:1) was added to trophozoite homogenates. For malondialdehyde (MDA) determination, the reaction was initiated by adding $\mathrm{HCl}$ to a $37 \% \mathrm{v} / \mathrm{v}$ final concentration and for the 4-hydroxynonenal (HNE) assay methanesulfonic acid and $\mathrm{FeCl}_{3}$ at $34 \mu \mathrm{M}$ (final concentration each) were used. The absorbance at $586 \mathrm{~nm}$ was measured upon incubation of the reaction mixture at $45^{\circ} \mathrm{C}$ for $40 \mathrm{~min}$. For each series of assays, the absorbance of a control containing water instead of a sample was always subtracted. For each assay homogenate, a control sample in which the reagent was replaced by acetonitrile/methanol $(3: 1, \mathrm{v} / \mathrm{v})$ was included. A standard curve of trimethoxypropane was used in all assays (GérardMonnier et al., 1998; Orozco-Ibarra et al., 2007).

\section{Detection of DNA Fragmentation}

Albendazole-sensitive trophozoites were incubated with different concentrations of $\operatorname{ABZ}(1.35,8$ and $250 \mu \mathrm{M})$, DMF or $\mathrm{H}_{2} \mathrm{O}_{2}$ $(100 \mu \mathrm{M})$ for $24 \mathrm{~h}$ at $37^{\circ} \mathrm{C}$, then washed twice in PBS $1 \mathrm{X}$ and incubated overnight at $42^{\circ} \mathrm{C}$ in a lysis solution $(10 \mathrm{mM}$ Tris-HCl, pH 7.4, 10 mM EDTA, 150 mM NaCl, 0.4\% sodium dodecyl sulfate, and $200 \mu \mathrm{g} / \mathrm{mL}$ proteinase $\mathrm{K}$ ). RNA was removed by incubating samples with $20 \mathrm{mg} / \mathrm{mL}$ RNase A at $37^{\circ} \mathrm{C}$ for $30 \mathrm{~min}$. The lysate was treated with phenol/chloroform (1:1) and nucleic acids were precipitated at $-20^{\circ} \mathrm{C}$ with $0.3 \mathrm{M}$ sodium acetate pH 7 and ethanol. After quantification, the extent of DNA fragmentation was analyzed by electrophoresis on $1 \%$ agarose/ethidium bromide gels (Ghosh et al., 2009).

\section{Detection of Oxidative DNA Damage}

DNA damage was assessed by immunofluorescence with an anti-8-hydroxydeoxyguanosine (8OHdG) monoclonal antibody (Santa Cruz Technologies, USA). ABZ-sensitive trophozoites treated with DMF, different concentrations of $\mathrm{ABZ}$ (1.35, 8, and $250 \mu \mathrm{M})$ or $\mathrm{H}_{2} \mathrm{O}_{2}(100 \mu \mathrm{M})$ for $16 \mathrm{~h}$ at $37^{\circ} \mathrm{C}$ were incubated for $1 \mathrm{~h}$ at $37^{\circ} \mathrm{C}$ on poly-L-lysine-coated $(2 \mathrm{mg} / \mathrm{ml})$ coverslips, rinsed twice with PBS and fixed with a solution of methanol:acetone $(1: 1 \mathrm{v} / \mathrm{v})$ at $-20^{\circ} \mathrm{C}$. Fixed cells were treated with $0.05 \mathrm{~N} \mathrm{HCl}$ for 5 min on ice, rinsed with PBS and washed with PBS containing 35,50 , and $75 \%$ ethanol consecutively for $3 \mathrm{~min}$ each time. DNA was denatured in situ with $0.15 \mathrm{~N} \mathrm{NaOH}$ in $70 \%$ ethanol for 4 min. The precipitate was rinsed twice with PBS and incubated with $0.2 \mu \mathrm{g} / \mathrm{ml}$ Hoechst dye for $10 \mathrm{~min}$. Subsequently parasites were washed with PBS containing 75, 50, and 35\% ethanol consecutively in the presence of $4 \%$ formaldehyde for 2 min each time. The samples were incubated in trypsin solution $(49.5 \mathrm{mM}$ Tris base, $1 \mathrm{mM}$ EDTA, $150.7 \mathrm{mM} \mathrm{Na} \mathrm{HPO}_{4}, 14.9 \mathrm{mM} \mathrm{K}_{2} \mathrm{HPO}_{4}$, $0.1 \%$ trypsin at $\mathrm{pH} 7.2$ ) for $10 \mathrm{~min}$ at $37^{\circ} \mathrm{C}$ and washed three times with PBS. Trophozoites were then incubated for $30 \mathrm{~min}$ with $1 \%$ bovine serum albumin (BSA) to block nonspecific binding and incubated with mouse monoclonal anti- 8-OHdG for $1 \mathrm{~h}$. After a wash with PBS, cells were incubated for $1 \mathrm{~h}$ at room temperature with goat anti-mouse IgG coupled to FITC (Santa Cruz Technologies, USA). Samples were analyzed using a 

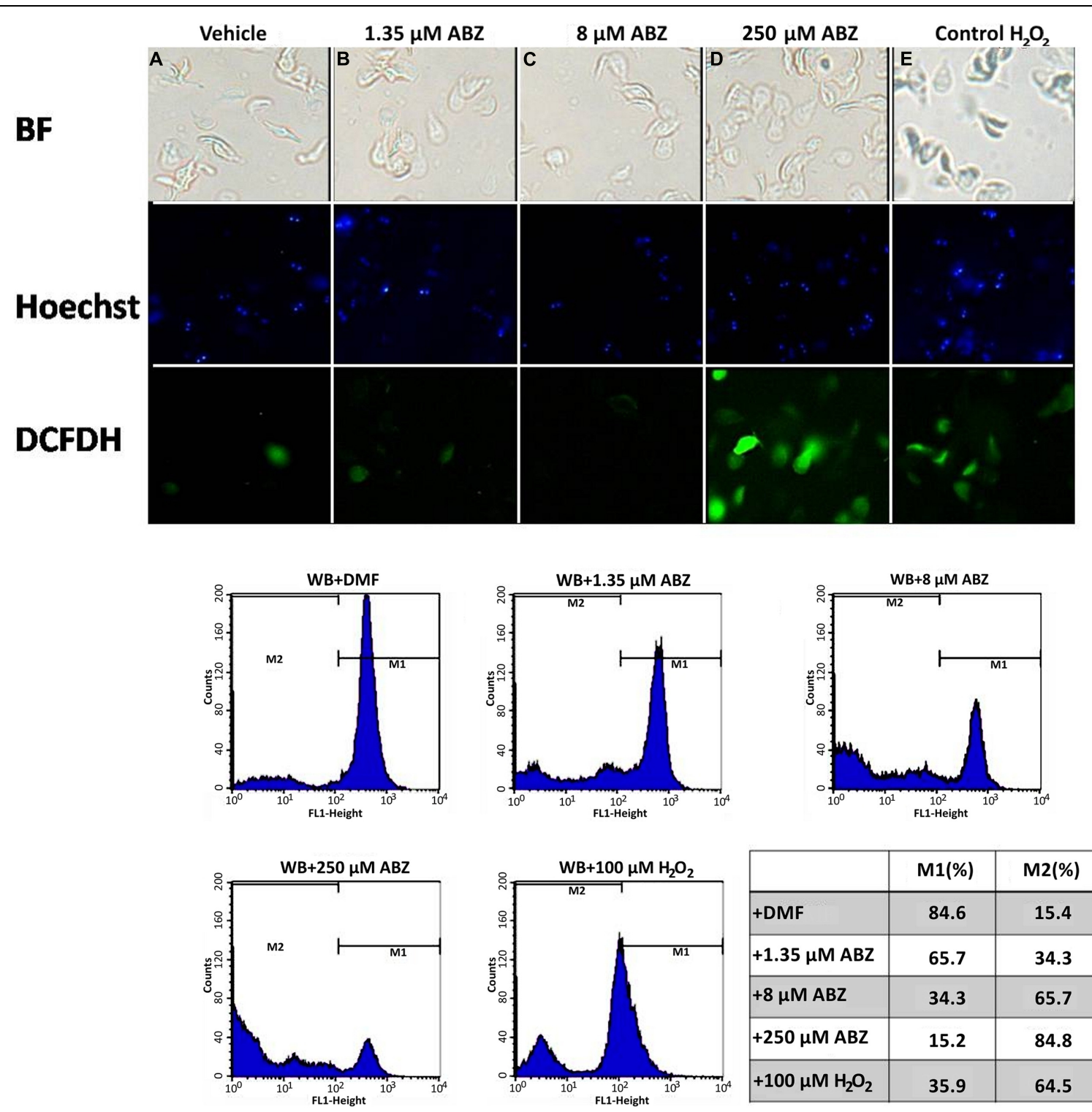

\begin{tabular}{|l|c|c|}
\hline & $M 1(\%)$ & $M 2(\%)$ \\
\hline$+D M F$ & 84.6 & 15.4 \\
\hline$+1.35 \mu \mathrm{M} \mathrm{ABZ}$ & 65.7 & 34.3 \\
\hline$+8 \mu \mathrm{M} \mathrm{ABZ}$ & 34.3 & 65.7 \\
\hline$+250 \mu \mathrm{M} \mathrm{ABZ}$ & 15.2 & 84.8 \\
\hline$+100 \mu \mathrm{M} \mathrm{H}_{2} \mathrm{O}_{2}$ & 35.9 & 64.5 \\
\hline
\end{tabular}

FIGURE 1 | Reactive oxygen species (ROS) are produced in Giardia duodenalis trophozoites exposed to Albendazole (ABZ). ABZ-sensitive Giardia strain (WB) was exposed to vehicle (DMF, A) and to $1.35 \mu \mathrm{M}$ (B), $8 \mu \mathrm{M}$ (C), or $250 \mu \mathrm{M}$ (D) of $\mathrm{ABZ}$ for $8 \mathrm{~h}$ at $37^{\circ} \mathrm{C}$, then $\mathrm{DCFDH}$ was added to monitor ROS production. In these experiments a control of intracellular ROS production was included. In this WB trophozoites were incubated with $100 \mu \mathrm{M} \mathrm{H}_{2} \mathrm{O}_{2}$ (E). Trophozoites micrographs are as follows: top panels bright field (BF), middle panel trophozoites' nuclei stained with Hoechst and lower panel trophozoites stained with DCFDH. The cells showed increased ROS production by ABZ treatment in comparison to control cells with no drug. Bottom panels are ROS production monitored by flow cytometry, the shift of fluorescence in $X$ axis indicates ROS production by live trophozoites (determined by Trypan blue exclusion) at the highest $\mathrm{ABZ}$ concentration. The table shows population percent in M1 (negative to ROS) and M2 (positive to ROS) according to flow cytometry data. Micrographs are from representative results of at least three experiments performed with independent batch cultures.
Zeiss microscope equipped with epifluorescence illumination as previously described (Suzuki et al., 2006).

\section{Detection of Protein-MDA Adducts and H2AX Phosphorylation by Western Blot}

Both protein-MDA adducts and histone $\mathrm{H} 2 \mathrm{AX}$ phosphorylation (at ser139) were evaluated by Western blot assays using specific antibodies. In these, ABZ-sensitive trophozoites were incubated with DMF, different concentrations of $\operatorname{ABZ}(1.35,8$, and $250 \mu \mathrm{M})$ or $\mathrm{H}_{2} \mathrm{O}_{2}(100 \mu \mathrm{M})$ for $24 \mathrm{~h}$ at $37^{\circ} \mathrm{C}$, washed with PBS tree times and suspended in lysis buffer. Twenty microgram of protein were analyzed by SDS-PAGE in 12\% acrylamide gels for the protein-MDA assay and in 15\% acrylamide gels for detection of H2AX phosphorylation. After electrophoresis, gels were transferred to nitrocellulose membranes. Membranes were blocked with PBS containing $0.1 \%$ Tween-20 and $1 \%$ skim milk for $2 \mathrm{~h}$ at $37^{\circ} \mathrm{C}$. After washing with Tris-buffered saline (TBS) membranes were incubated with rabbit anti-MDA (Abcam, USA) 
A

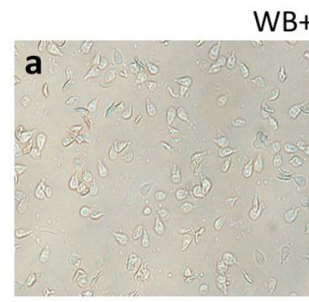

B
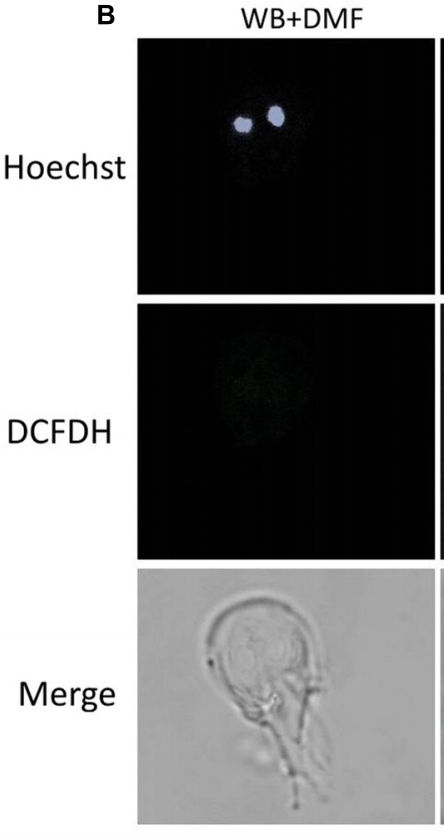

WB+DMF

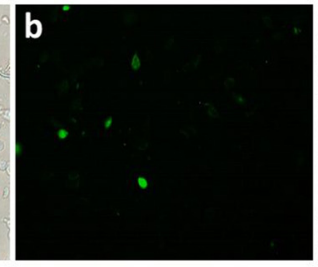

$\mathrm{WB}+1.35 \mu \mathrm{M} \mathrm{ABZ}$
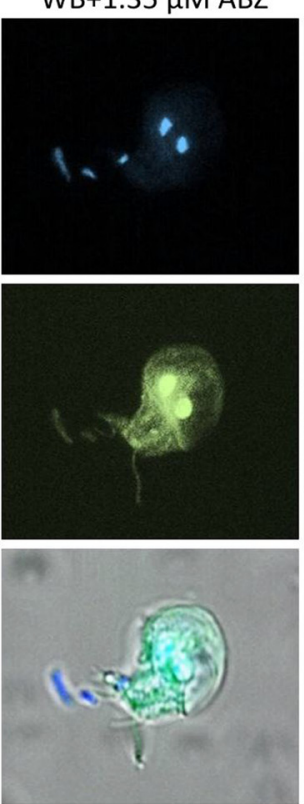

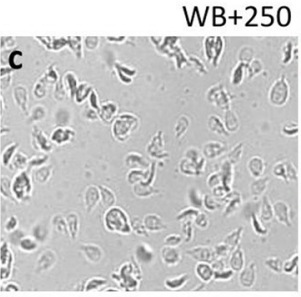

$W B+250 \mu \mathrm{M} A B Z$
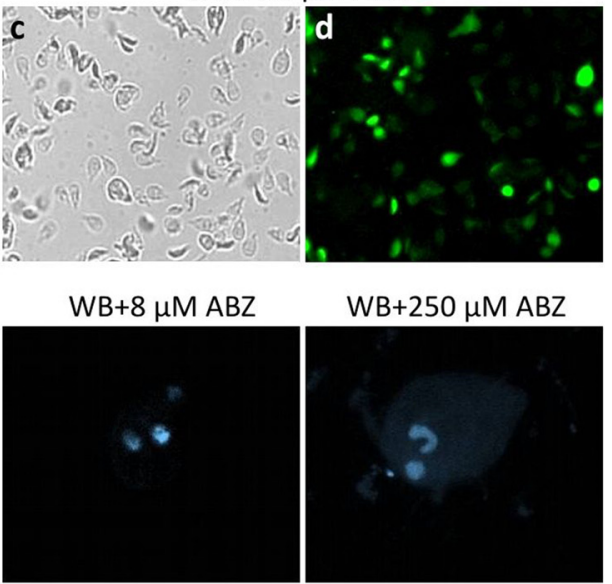

$\mathrm{WB}+250 \mu \mathrm{M} \mathrm{ABZ}$
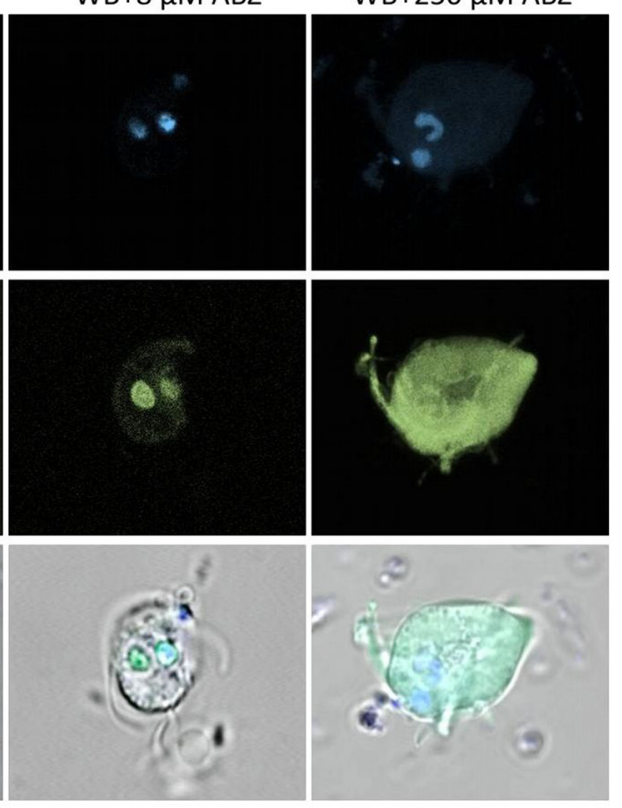

FIGURE 2 | Intracellular localization of ROS production in G. dudodenalis trophozoites exposed to ABZ. WB Giardia trophozoites were exposed to DMF or to the indicated ABZ concentrations (from left to right: 1.35, 8, and $250 \mu \mathrm{M}$ ) for $8 \mathrm{~h}$ at $37^{\circ} \mathrm{C}$. Cells were then incubated with DCFDH. Trophozoite micrographs are as follows: (A) top panel: representative images of trophozoites exposed to DMF $(a, b)$ or to $250 \mu$ M ABZ (c,d) and then incubated with DCFDH. Morphological changes in trophozoites (c BF) and ROS localization (d epifluorescence illumination) are evident in ABZ treated cells. (B) Images of representative individual cells. Top panel trophozoites' nuclei stained with Hoechst, middle panel trophozoites incubated with DCFDH (epifluorescence illumination) and lower panel merged cell images. At the lowest concentrations, ROS production is restricted to nuclei, whereas at the highest ABZ concentration, this is detected all over the cytoplasm. The micrographs are representative of at least three independent experiments. and rabbit anti-H2AX (Millipore, USA) antibodies for $1 \mathrm{~h}$ at room temperature under constant shaking. Membranes were washed and incubated with horseradish peroxidase-conjugated mouse anti-rabbit IgG (Thermo, USA). Chemiluminescence detection was performed with the Amersham ECL detection kit according to manufacturer's instructions (Hofśtetrová et al., 2010; Moore et al., 2013).

\section{Identification and Quantification of Apoptotic and Necrotic Cells}

The cells undergoing apoptotic or necrotic processes after ABZor $\mathrm{H}_{2} \mathrm{O}_{2}$ exposure were analyzed by flow cytometry in which fluorescence by annexin $\mathrm{V}$ binding (green) and propidium iodide (PI) uptake (red) were quantified. Positioning of quadrants on annexin V/PI dot plots was analyzed according to the following pattern: living cells (annexin V-/PI-), early apoptotic/primary apoptotic cells (annexin $\mathrm{V}+/ \mathrm{PI}-$ ), late apoptotic/secondary apoptotic cells (annexin $\mathrm{V}+/ \mathrm{PI}+$ ) and necrotic cells (annexin
$\mathrm{V}-/ \mathrm{PI}+)$. The assay was carried out using the Annexin V-FITC Apoptosis Detection Kit (BioVision, USA) following the manufacturer's instructions. Briefly, cells were incubated with DMF, different concentrations of $\operatorname{ABZ}(1.35,8$, and $250 \mu \mathrm{M})$ or $\mathrm{H}_{2} \mathrm{O}_{2}(100 \mu \mathrm{M})$ for $24 \mathrm{~h}$. Then, trophozoites were centrifuged at $440 \times g$ at $4^{\circ} \mathrm{C}$ and suspended in $500 \mu \mathrm{l}$ of $1 \mathrm{X}$ binding buffer. Cells were then incubated with $5 \mu \mathrm{l}$ of annexin V-FITC and $5 \mu \mathrm{l}$ of PI $(50 \mu \mathrm{g} / \mathrm{ml})$ for $5 \mathrm{~min}$ in the dark at room temperature. The FITC and PI fluorescence was measured with a FACS Calibur Flow Cytometer equipped with an FL-1 filter $(530 \mathrm{~nm})$ and an FL-2 filter (585 nm), respectively, in at least 10,000 events (Ghosh et al., 2009) in each experiment.

\section{Determination of Cell Cycle Stages in \\ G. duodenalis Trophozoites Exposed to ABZ}

To determine the proportions of trophozoites at the different cycle stages, nuclear staining with PI was coupled to flow cytometry. In brief, ABZ-sensitive trophozoites were exposed to 

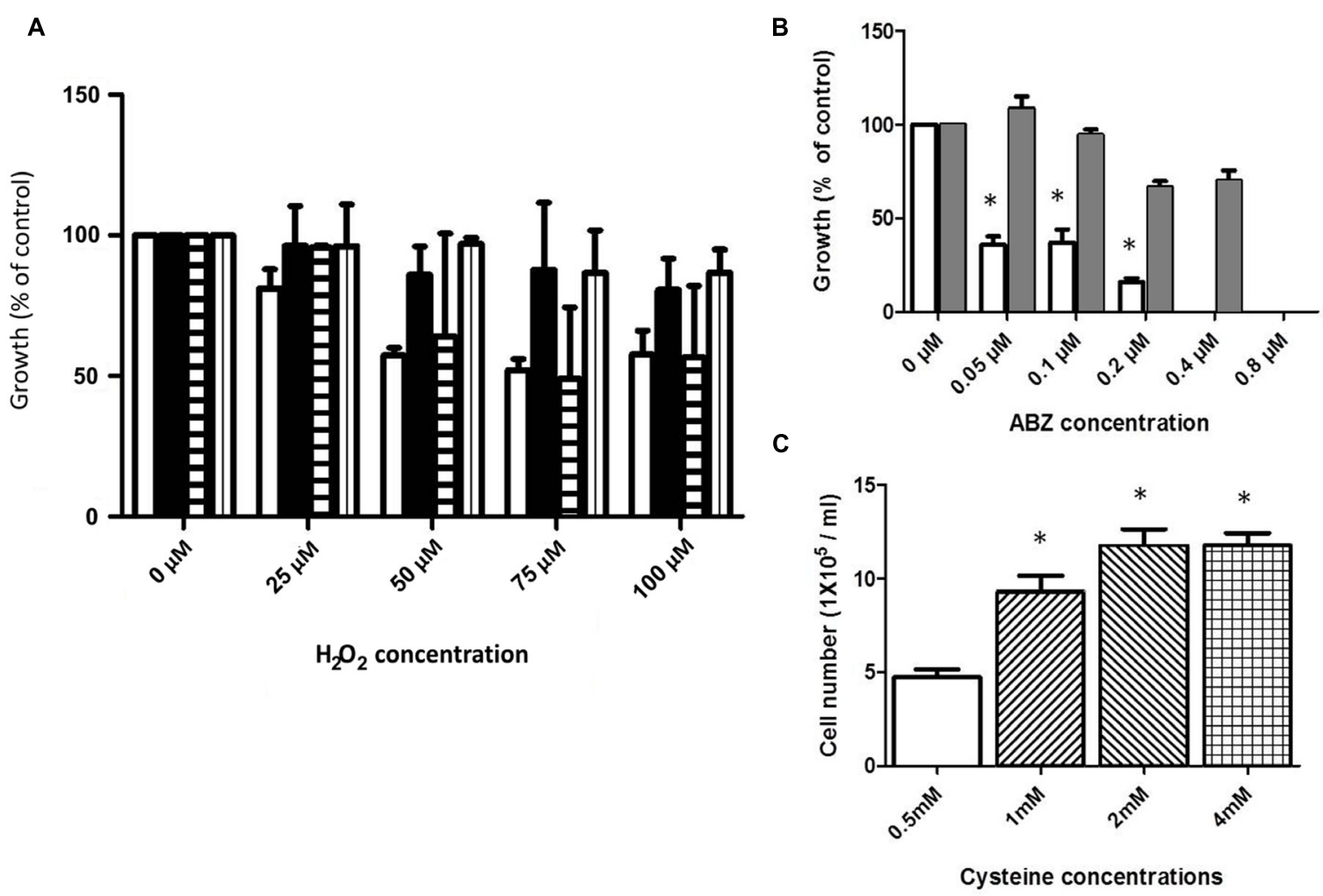

FIGURE 3 | Cross-resistance to $A B Z$ and $\mathrm{H}_{2} \mathrm{O}_{2}$ and cysteine (Cys) protection in trophozoites exposed to $\mathbf{A B Z}$. (A) Cross-resistance to $\mathrm{H}_{2} \mathrm{O}_{2}$ was evaluated in the ABZ-resistant clones R1.35 (black bars), R.8 (horizontal lined bars), and R.250 (vertical lined bars) previously obtained in our group (Paz-Maldonado et al., 2013). Parasites were exposed to the indicated $\mathrm{H}_{2} \mathrm{O}_{2}$ concentrations for $24 \mathrm{~h}$ and the cell number was determined by SYTOX Green. As control, wild type WB strain (white bars) was incubated with the indicated $\mathrm{H}_{2} \mathrm{O}_{2}$ concentration. (B) Cross-resistance to $\mathrm{ABZ}$ in a $\mathrm{H}_{2} \mathrm{O}_{2}$-resistant $\mathrm{G}$. dudodenalis. $\mathrm{A} \mathrm{H}_{2} \mathrm{O}_{2}$-resistant Giardia strain $(\mathrm{ROX})$ was obtained by sub-culturing the WB strain in increasing $\mathrm{H}_{2} \mathrm{O}_{2}$ concentration for 6 months. Control WB (white bars) and ROX (gray bars) trophozoites were exposed to the indicated increasing $A B Z$ concentrations for $24 \mathrm{~h}$ and the cell number was determined using the fluorescent tracer SYTOX Green. The ROX strain showed cross-resistance to ABZ. (C) Cysteine protection of Giardia trophozoites exposed to ABZ. WB trophozoites were incubated in growth medium with $0.5 \mathrm{mM}$ (white bar), $1 \mathrm{mM}$ (lined up to the right bar), $2 \mathrm{mM}$ (lined up to the left bar), or $4 \mathrm{mM}$ (boxed bar) of cysteine for $24 \mathrm{~h}$ and then trophozoites were further incubated with $0.2 \mu \mathrm{M} \mathrm{ABZ}$ for $48 \mathrm{~h}$. In all graphs the results are the mean $\pm S D$ of at least three independent experiments. In graphs $(\mathbf{B}, \mathbf{C}) *$ indicates $p \leq 0.05$ by ANOVA and Tukey's analysis in which values obtained with WB trophozoites were compared with values obtained in ROX trophozoites exposed to the different ABZ concentrations (B). (C) Values obtained in WB trophozoites treated with $0.5 \mathrm{mM}$ cysteine were compared to values obtained in WB trophozoites treated with different cysteine concentrations and then exposed to $A B Z$. different concentrations of $\operatorname{ABZ}(1.35,8$, and $250 \mu \mathrm{M})$ for $4 \mathrm{~h}$ at $37^{\circ} \mathrm{C}$, washed with PBS and fixed $30 \mathrm{~min}$ with $70 \%$ ethanol in PBS. Then cells were washed again and incubated in PBS containing $0.1 \mathrm{mg} / \mathrm{mL}$ RNAase overnight at $4^{\circ} \mathrm{C}$. Finally cell pellets were washed, stained with PI ( $1 \mu \mathrm{M}$ in PBS), washed and resuspended in small volume $(200-300 \mu \mathrm{L})$ for analysis in a FACS Calibur Flow Cytometer in at least 10,000 events per sample. The histogram areas were identified as reported by Reaume et al. (2013).

\section{Statistical Analyses}

All the data were obtained from at least three experiments and where indicated the results are expressed as mean $\pm \mathrm{SD}$. Inter-group variation was assessed by one-way analysis of variance (ANOVA) followed by Tukey's multiple comparison test. Statistical significance was determined if $p \leq 0.05$.

\section{Results}

\section{Intracellular ROS Formation}

In some reports using animal models $\mathrm{ABZ}$ was shown to produce oxidative damage (Locatelli et al., 2004; Bártíková et al., 2010). In $G$. duodenalis oxidative stress damage has been induced using pro-oxidant compounds such as $\mathrm{H}_{2} \mathrm{O}_{2}$ (Ghosh et al., 2009; Raj et al., 2013) in which intracellular ROS formation hallmarks this phenomenon. ABZ-exposed parasites showed greater ROS signals than parasites not exposed to the drug (Figure 1, top panels). The effect was mainly detected at the highest ABZ concentration tested $(250 \mu \mathrm{M})$, however, ROS formation could be determined by flow cytometry at lower concentrations (Figure 1, bottom panels).

To determine the localization of intracellular ROS formation within the trophozoites confocal microscopy was used. In these experiments the typical altered morphology caused by 
A

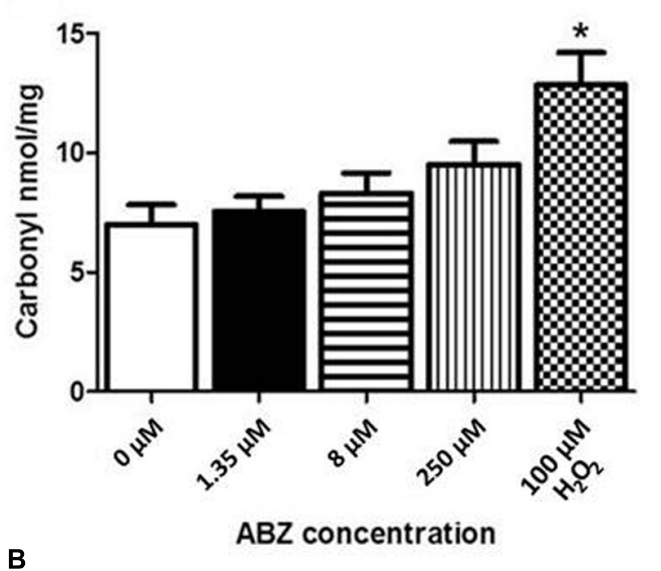

B

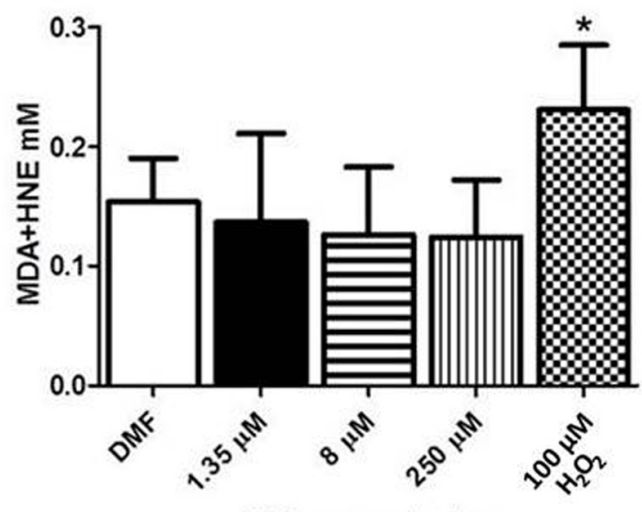

$A B Z$ concentration
C

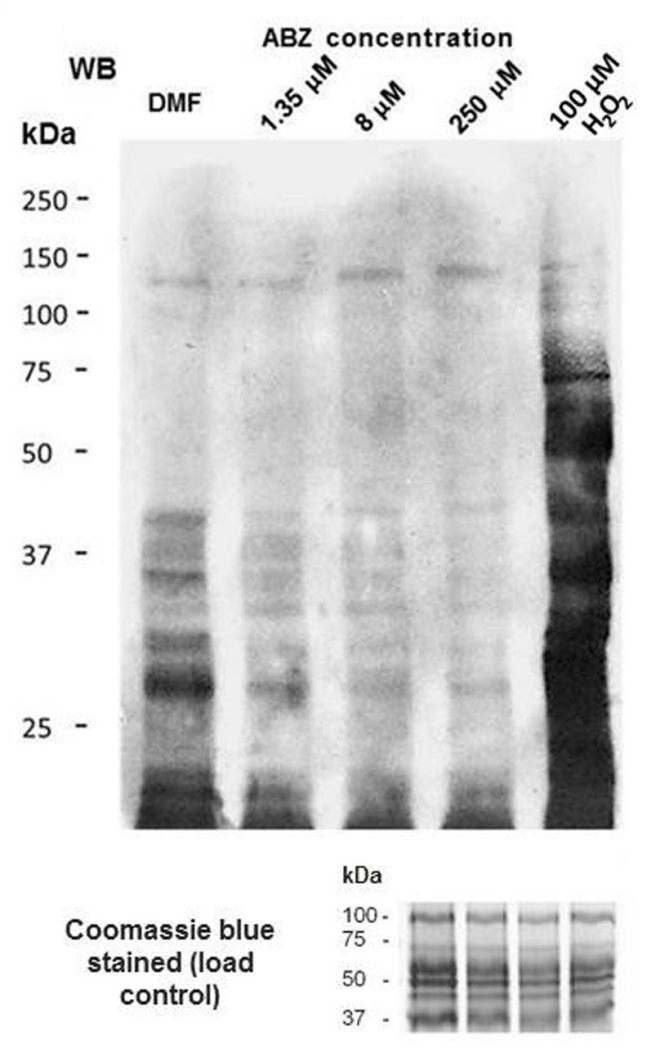

trophozoites were exposed to the different $A B Z$ concentrations as indicated in (A). HNE or MDA were determined by absorbance at $586 \mathrm{~nm}$. The values in $\mathbf{( A , B )}$ are the mean $\pm \mathrm{SD}$. ${ }^{*} p \leq 0.05$ by ANOVA and Tukey's analysis in which values obtained with trophozoites treated with the different $A B Z$ concentrations were compared to values obtained with the DMF treated parasites. (C) MDA-protein adducts were detected by Western blot in the same trophozoites samples treated with the indicated ABZ concentrations using rabbit anti-MDA antibodies. At the bottom of panel (C) the Coomassie blue stained gel is included and shows that similar protein amounts of each sample were loaded. benzimidazoles (Paz-Maldonado et al., 2013) was observed in ABZ-treated trophozoites (Figure 2A top panel c). In these cells ROS formation was also evident in most cells as determined by fluorescent staining (Figure 2A top panel $\mathrm{d}$ ). When individual cells were observed the trophozoites' nuclei were determined as the primary site of ROS formation (Figure 2B) as judged by fluorescent staining at low ABZ concentrations used (1.35 $\mu \mathrm{M}$ and $8 \mu \mathrm{M})$. At the highest drug concentration used $(250 \mu \mathrm{M})$ there was a widespread distribution of ROS throughout the trophozoite cytoplasm (Figure 2B middle panel).

\section{Cross Resistance to $A B Z$ and $\mathrm{H}_{2} \mathrm{O}_{2}$ in Giardia Trophozites}

The ABZ-resistant clones, namely R1.35, R.8, and R.250 (Argüello-García et al., 2009; Paz-Maldonado et al., 2013) were used to determine whether cross-resistance to classical oxidative stressor $\left(\mathrm{H}_{2} \mathrm{O}_{2}\right)$ and $\mathrm{ABZ}$ was induced in the resistant trophozoites. For this purpose the ABZ-resistant clones were incubated under increasing concentrations of $\mathrm{H}_{2} \mathrm{O}_{2}$, and cell growth was determined. In general the resistant clones R1.35 and R.250 showed a tendency to increased resistance to $\mathrm{H}_{2} \mathrm{O}_{2}$ induced death in comparison to the ABZ-susceptible WB strain (Figure 3A). A special case is the R8 resistant strain which frequently behave, in this and other studies, as a "transition state" between low and high $\mathrm{ABZ}$ resistance depending on the parameter that is evaluated (see also Figure 6A; Argüello-García et al., 2009; Paz-Maldonado et al., 2013)

Resistance to $\mathrm{H}_{2} \mathrm{O}_{2}$ was achieved by using continuous trophozoite subcultures under increasing concentrations of $\mathrm{H}_{2} \mathrm{O}_{2}$. Following this procedure for approximately 6 months, a 


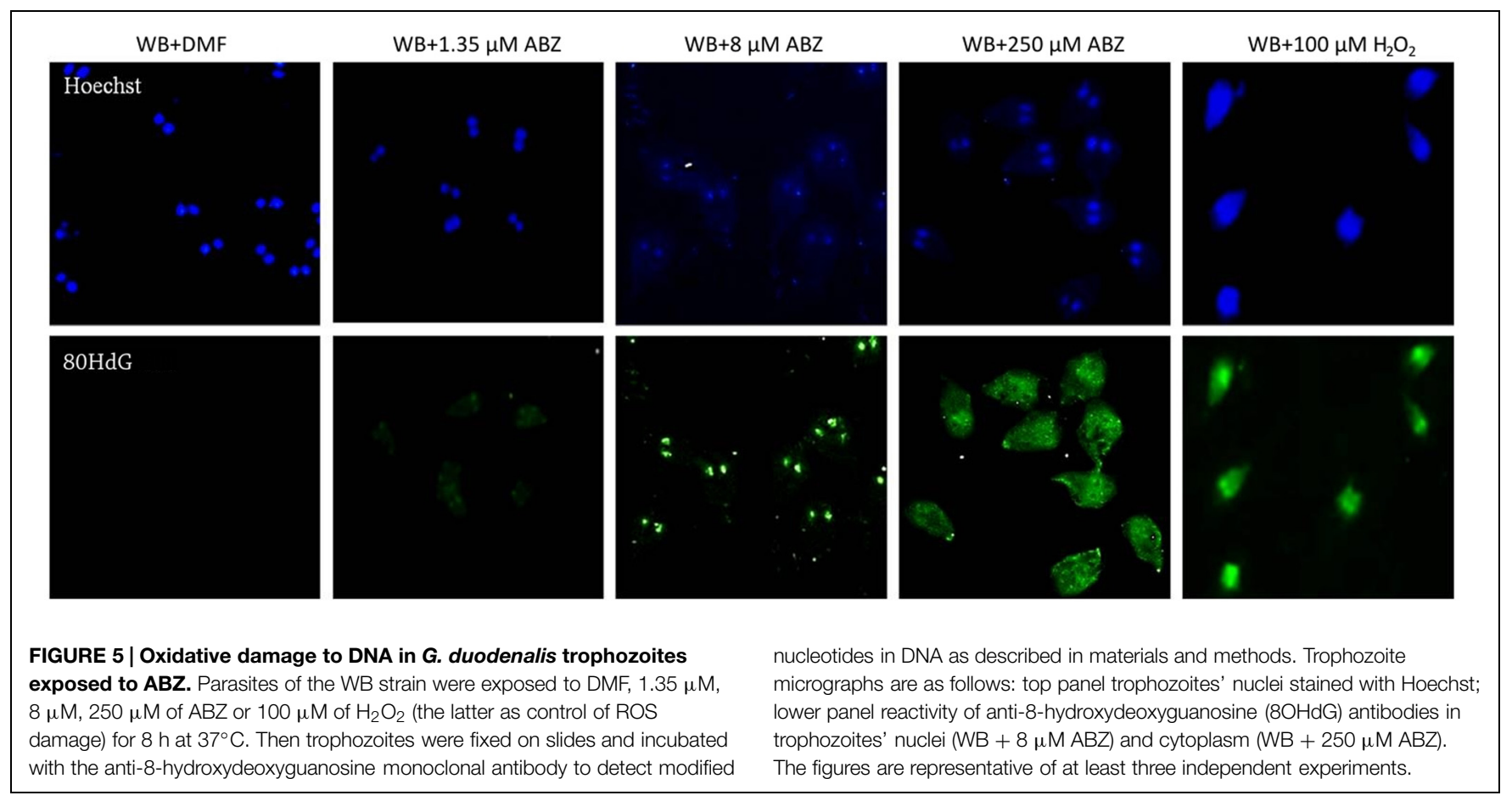

strain displaying resistance to $75 \mu \mathrm{M} \mathrm{H}_{2} \mathrm{O}_{2}$ was obtained (ROX). This strain was incubated in the presence of $\mathrm{ABZ}$ showing a significantly higher growth rate as compared with the $\mathrm{H}_{2} \mathrm{O}_{2}$ susceptible WB strain (Figure 3B).

\section{Cysteine Increases Tolerance to $A B Z$ in the Drug Treated Trophozoites}

Giardia duodenalis possesses a bacterial-like antioxidant metabolism in which cysteine is the major antioxidant thiol instead of glutathione. To test if increased levels of extracellular cysteine may confer increased tolerance to the drug in ABZsusceptible trophozoites, these clones were incubated in culture media containing different cysteine concentrations and subsequently ABZ at $0.2 \mu \mathrm{M}$ was added and after $48 \mathrm{~h}$-incubation trophozoite growth was measured. As a result, parasites incubated at cysteine concentrations higher than $1 \mathrm{mM}$ showed higher growth after ABZ exposure than those incubated at lower concentrations of this amino acid (Figure 3C). These results suggest that cysteine may help to contend the ROS damage upon ABZ exposure.

\section{Damage to Biomolecules after ABZ Exposure in G. duodenalis Trophozoites}

The formation of intracellular ROS may trigger oxidative damage to various biomolecules such as proteins, lipids, and DNA. Protein carbonylation was determined in ABZ-sensitive trophozoites exposed to increasing ABZ concentrations. As can be seen in Figure 4A, a consistent but not statistically significant increase in protein carbonylation correlated with the increase in drug concentration, confirming the presence of oxidative damage by ABZ treatment in cellular proteins of $G$. duodenalis.
The levels of lipid peroxidation in healthy cells are maintained under controlled limits but these can be affected, i.e., increased, when cells are treated with pro-oxidant xenobiotics. This process leads to the formation of some intermediates such as MDA and HNE. The determination of such intermediates was carried out after ABZ exposure of drug-sensitive trophozoites. In both cases there was not a significant change in ABZ-treated parasites as compared with untreated cultures contrary to the drug susceptible clones exposed to $\mathrm{H}_{2} \mathrm{O}_{2}$ used as a control (Figure 4B). This observation was further corroborated using antibodies detecting MDA-protein adducts which displayed more intense staining only when drug susceptible trophozoites were exposed to $\mathrm{H}_{2} \mathrm{O}_{2}$ (Figure 4C).

Oxidative damage to DNA by ABZ treatment was determined by immunocytochemistry assays using antibodies against 8OHdG. In these, a significant increase in intranuclear staining, denoting 8-OHdG-containing DNA in ABZ-treated cells was observed (Figure 5). At the highest drug concentrations used $(250 \mu \mathrm{M})$ the fluorescent signal was observed in nucleus and the entire cytosol displayed a diffuse pattern with a punctuated pattern in some regions within the trophozoites (Figure 5).

\section{Characterization of DNA Damage in G. duodenalis Trophozoites Induced by ABZ}

From the previous observations we concluded that ABZ caused a preferential oxidative damage at the DNA level over other biomolecules which could be severe as judged by the extra nuclear $8 \mathrm{OHdG}$ detection at higher $\mathrm{ABZ}$ concentrations. To assess damage to DNA integrity, genomic DNA was purified from control and ABZ-exposed trophozoites and analyzed in agarose gels to assess its integrity (presence of a high-sized band) or partial/total degradation. As shown in Figure 6A, genomic DNA 


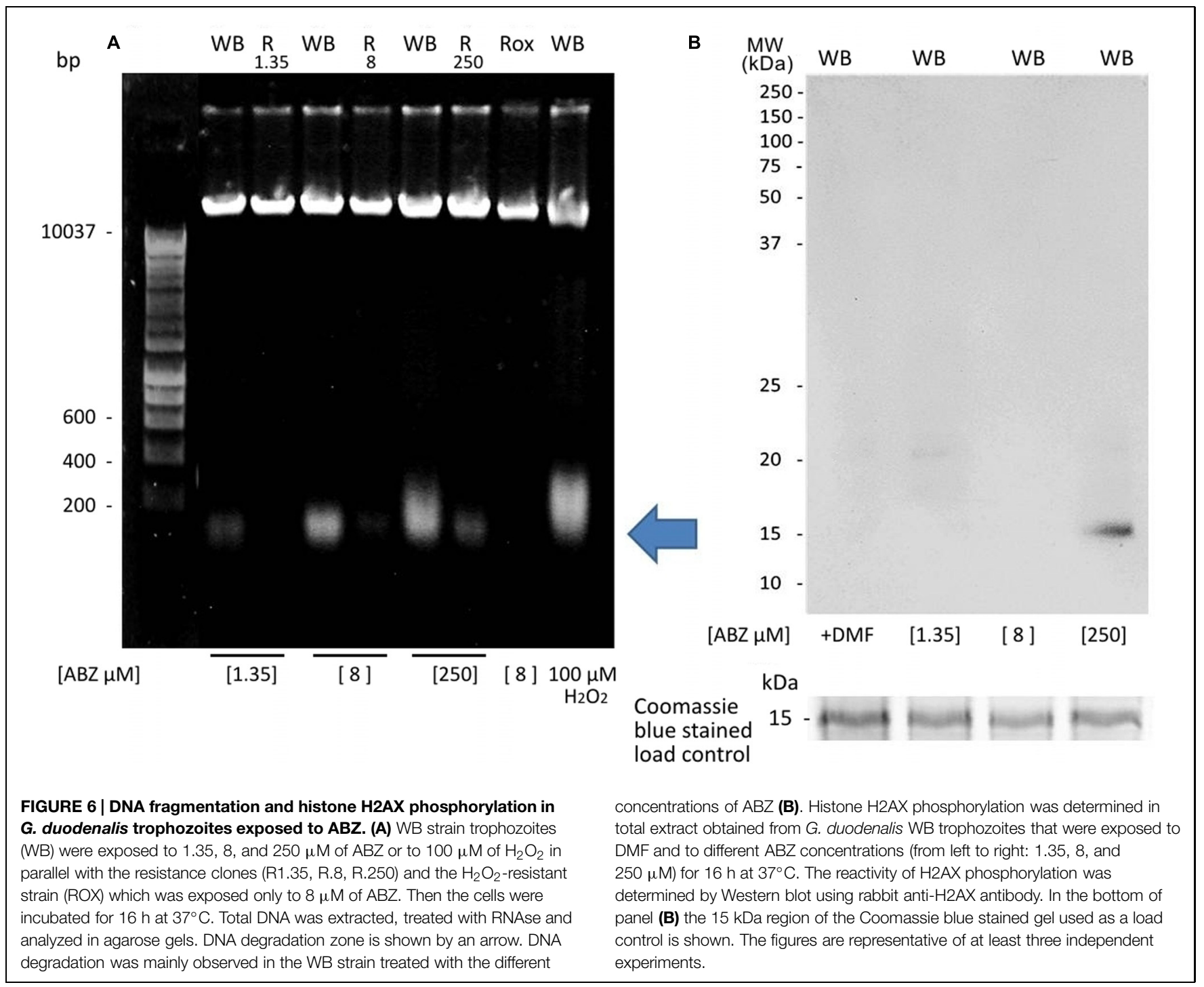

was broken down in ABZ-exposed trophozoites as determined by the presence of diffuse and low molecular weight bands. This DNA degradation was absent or present at a lesser extent in the ABZ- and ROX-resistant strains. To further confirm the damage to the double stranded DNA, anti-histone H2AX antibodies were used. This protein becomes phosphorylated upon DNA doublestrand break. In Figure 6B it is shown that exposure of parasites to the highest $\mathrm{ABZ}$ concentration $(250 \mu \mathrm{M})$ induced a H2A signal indicating damage to DNA. The level of phosphorylated Giardia $\mathrm{H} 2 \mathrm{~A}$ was proportional to the DNA damage, therefore the signal was better observed at the highest concentration of ABZ.

\section{ABZ Induces Apoptosis-Like Death and Partial Cell Cycle Arrest in G. duodenalis Trophozoites}

To determine if ABZ causes necrosis or an apoptoticlike phenomenon, the translocation of phosphatidylserine in ABZ treated trophozoites was detected using anti-annexin $V$ antibodies as a specific marker of early apoptosis. Trophozoites exposed to ABZ displayed a significant increase in annexin $V$ staining. At higher drug concentration a significant number of cells positive to both markers indicated a process of cell death involving late apoptosis and necrosis (Figure 7). In further experiments the trophozoites nuclei were stained with PI to assess if $\mathrm{ABZ}$ exposure may alter the cell cycle progression between control and ABZ-exposed trophozoites. As can be observed in Figure 8, ABZ produced a noticeable and consistent decrease in the G1 subpopulation (yellow area, from $14.6 \%$ in vehicletreated cells to $2.7 \%$ in $250 \mu \mathrm{M}$ ABZ-treated cells), a slight decrease in the $S$-phase subpopulation in $1.35 \mu \mathrm{M}$ ABZ-treated cells as compared to DMF-treated cells (stripped area, from 27 to $22.1 \%$, respectively) and a moderated increase in G2 subpopulation between these same samples (blue area, from 61.0 to $69.9 \%$, respectively). The cells treated with $8 \mu \mathrm{M} \mathrm{ABZ}$ displayed a similar distribution to the one observed in the population exposed to $250 \mu \mathrm{M} \mathrm{ABZ}$. These data suggest that cytotoxic ABZ concentrations allow only a partial $\mathrm{G} 1 \rightarrow \mathrm{S} \rightarrow \mathrm{G} 2$ transit in cells in a pattern $(\mathrm{G} 2>>\mathrm{S}>\mathrm{G} 1>\mathrm{M})$ that indicates an arrested state at the $\mathrm{G} 2 / \mathrm{M}$ phase boundary. 


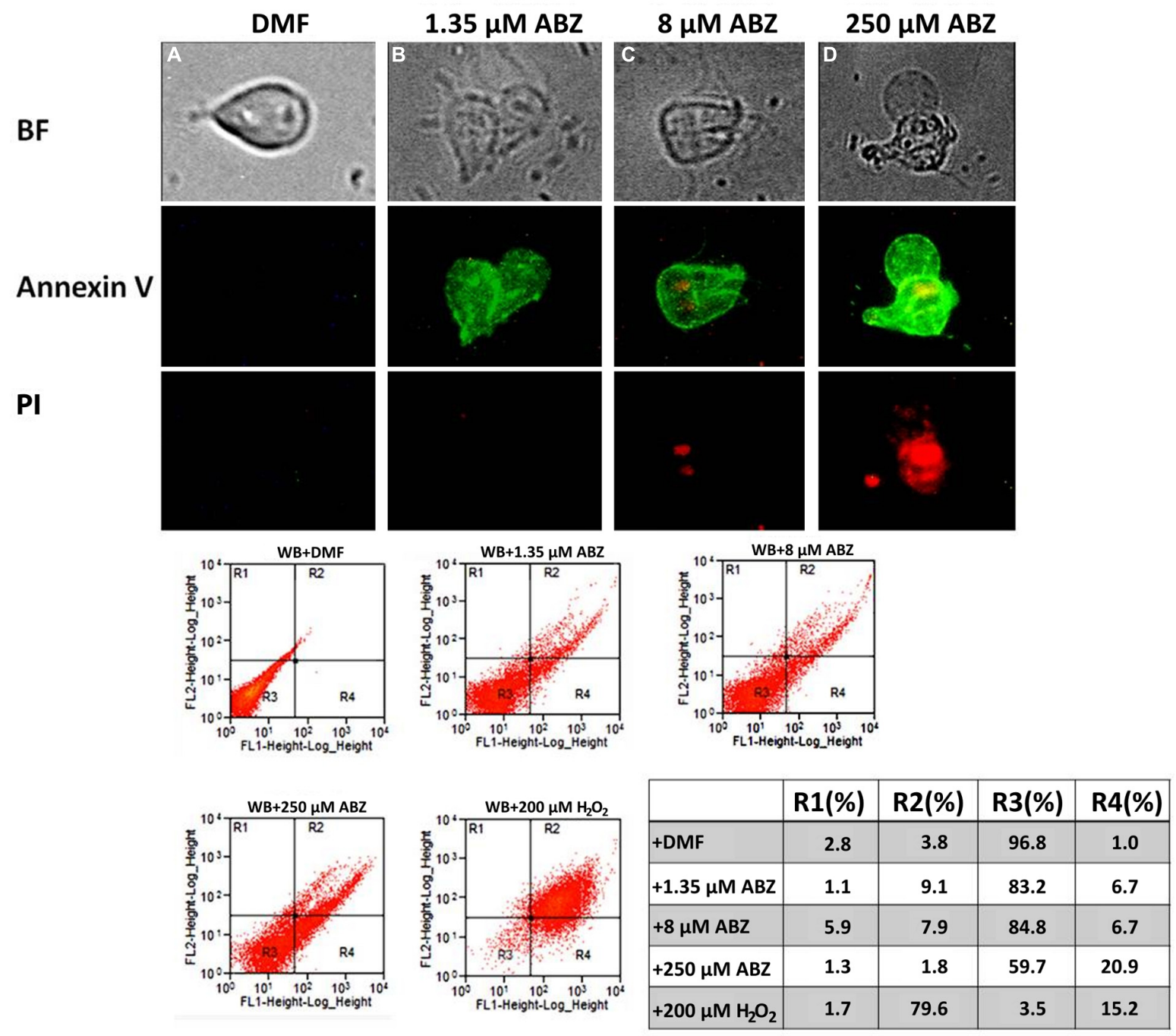

FIGURE 7 | Albendazole induces apoptosis-like death in Giardia. Annexin $\checkmark$ binding in the parasite's cell surface (as indicator of early apoptosis) was detected as a consequence of translocation of phosphatidylserine to the plasmatic membrane (middle panel). The parasites were exposed to DMF (A), $1.35 \mu \mathrm{M}$ (B), $8 \mu \mathrm{M}$ (C), $250 \mu \mathrm{M}$ (D) of $\mathrm{ABZ}$ for $16 \mathrm{~h}$ at $37^{\circ} \mathrm{C}$. Then annexin V-FITC and PI (indicator of late apoptosis and necrosis) were added to the medium. Trophozoites' micrographs are as follows: top panel: in BF; bottom panel: trophozoites stained with annexin V-FITC and PI. The FITC and PI fluorescence was determined using a FACS Calibur Flow Cytometer. Data shown in the figure are as follows: quadrant R1 are cells positive for necrosis; quadrant R2 are cells positive for necrosis and apoptosis; quadrant R3 are cells negative for both markers; quadrant $\mathrm{R} 4$ are cells positive for early apoptosis. As control, flow cytometry was performed with WB cells exposed to $200 \mu \mathrm{M} \mathrm{H}_{2} \mathrm{O}_{2}$. The figures are representative of at least three independent experiments. The table shows population percent in each quadrant according to flow cytometry data.

\section{Discussion}

Parasitic diseases by protozoa and helminths represent a serious health problem worldwide. The control of the infections caused by these parasites is carried out mainly by drug treatment. The drug ABZ is a broad spectrum benzimidazole with an anti-helminthic effect and its low cost makes this drug a suitable candidate for mass drug administration programs to deworm children in countries where giardiasis is endemic as well. However, up to five $400 \mathrm{mg}$ doses are needed to clear infections by $G$. duodenalis, limiting the utility of these campaigns to diminish burdens of giardiasis. Also, the use of suboptimal doses may engender and disseminate ABZ-resistant Giardia (Tian et al., 2010; Watkins and Eckmann, 2014). Likewise many parasites including Giardia exhibit cross-resistance to diverse drugs. Therefore, it is essential to understand the mechanisms involved in the toxicity of the drugs used; this understanding can help to devise high efficiency regimes and new and effective drugs against resistant strains (Watkins and Eckmann, 2014). Understanding the mechanisms of the effects of ABZ on Giardia will also help to define at least in part, the ABZ toxicity reported in some patients particularly in the liver, as well as other side effects such as possible teratogenisis (Dayan, 2003; Nandi and Sarkar, 2013). 

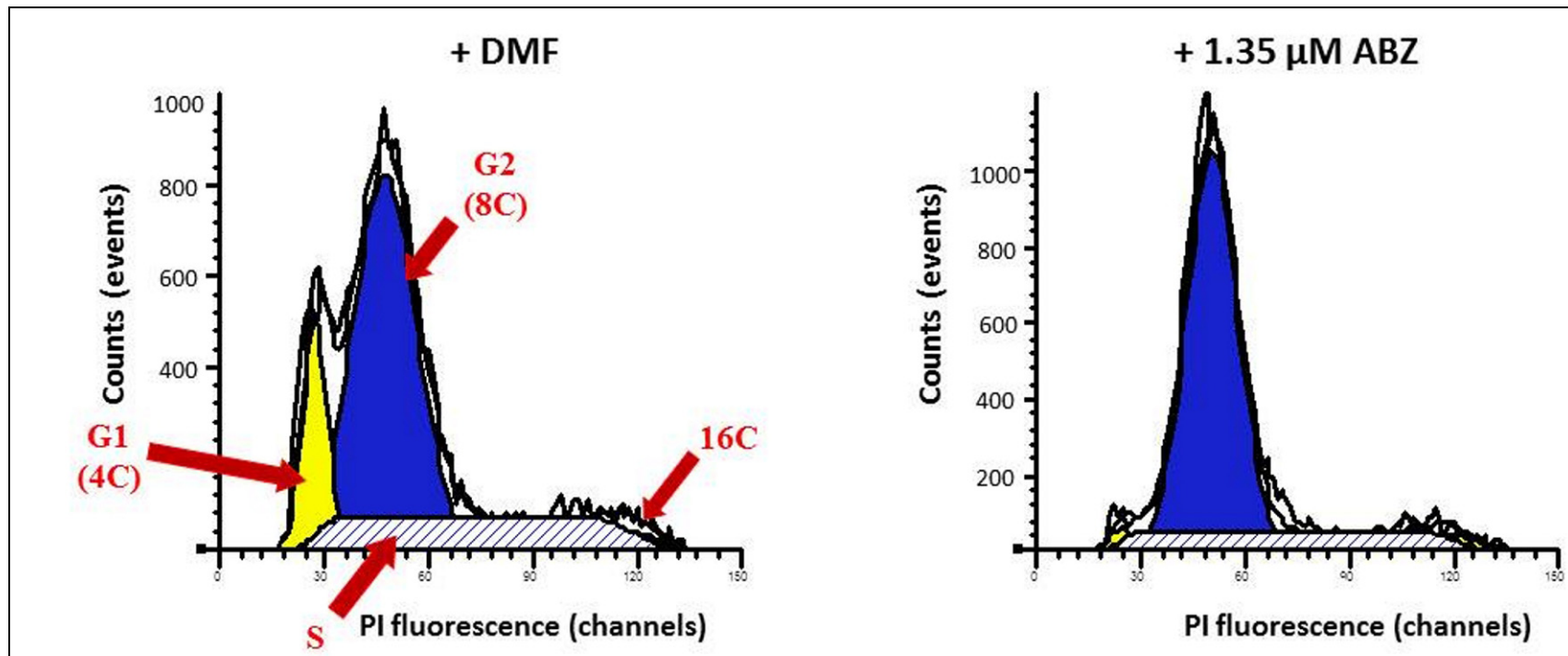

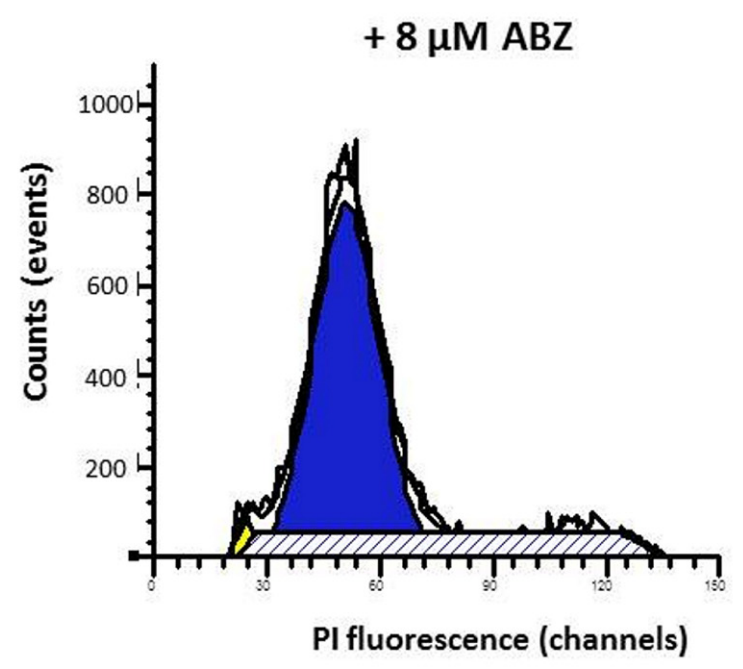

FIGURE 8 | Cell cycle stages determined by flow cytometry analysis in G. duodenalis trophozoites exposed to ABZ. Parasites were exposed to DMF (control) and to different ABZ concentrations (1.35, 8, and $250 \mu \mathrm{M})$ for $4 \mathrm{~h}$ at $37 \circ \mathrm{C}$. Then cells were stained with propidium iodide $(\mathrm{PI})$ and $\mathrm{PI}$ fluorescence

In this context, the mechanisms of $\mathrm{ABZ}$ action have been studied mainly in helminthic parasites and information in protozoans is limited. The main mechanism of $\mathrm{ABZ}$ action involves binding to $\beta$-tubulin causing the destabilization of the cytoskeleton. In this regard, resistance to ABZ has been associated with point mutations in this protein and so far other effects of ABZ have received little attention. Some studies in mammalian cells have correlated the use of $\mathrm{ABZ}$ to the presence of oxidative stress. Since the susceptibility of many parasites to oxidative stress has been reported (Pal and Bandyopadhyay, 2012), in this study we have evaluated the capacity of ABZ to induce oxidative stress in the protozoan parasite G. duodenalis.

The results indicated that ABZ exposure induced intracellular ROS formation in drug susceptible trophozoites and interestingly ROS were detected mainly in the nuclei. Therefore, oxidative-stress caused by $\mathrm{ABZ}$ can be part of the cytotoxic effect of this drug in Giardia. An important aspect to be addressed in future studies is to determine which ROS are involved as well as the mechanisms inducing their formation.

Since ABZ cytotoxicity was herein related to oxidative stress, another pro-oxidant molecule $\left(\mathrm{H}_{2} \mathrm{O}_{2}\right)$ was evaluated. Of note, a partial degree of cross-resistance to this agent was detected in the ABZ-resistant clones suggesting that similar antioxidant responses may be induced by each compound. This correlation between drug resistance and antioxidant response has also been suggested in drug resistant Leishmania strains (Berg et al., 2015) and in other pathogens such as 
Plasmodium and Pseudomonas (Lehane et al., 2012; Poole, 2014). The phenomenon of cross-resistance in Giardia to different drugs including metronidazole and ABZ has already been reported (Müller et al., 2007) although the causes of this have not yet been fully elucidated. The protection conferred by cysteine in ABZ-treated trophozoites further suggests that this drug induces some toxicity through oxidative stress thus cysteine may provide a reductive environment, however, the mechanisms involved in this protective effect remains to be elucidated. Interestingly in a recent study of our group, a set of antioxidant enzymes present in Giardia (e.g., NADH oxidase, flavoprotein-A, superoxide reductase, peroxiredoxins, Li and Wang, 2006; Mastronicola et al., 2014) have shown an increased expression along to increased intracellular cysteine concentrations in the ABZ-resistant clones used in this study (Argüello-García et al., 2015). Other processes as drug metabolization could also play a role in resistance because Giardia apparently has metronidazole-activating enzymes (nitro reductases; Pal et al., 2009) and ABZ metabolites (sulphoxide and sulphone) have been detected in this parasite (Oxberry et al., 2000). Interestingly these are accumulated in lower levels in the ABZ-resistant clones (Argüello-García et al., 2015).

Regarding the damage promoted by ABZ in trophozoites, two interesting findings were observed: (a), the lack of lipid peroxidation and protein carbonylation, and (b) the presence of DNA damage as a main mechanism of the cytotoxic effect of ABZ. The lack of lipid peroxidation may be due either to the fact that Giardia uptakes lipids and cholesterol from exogenous sources, to the unique lipid metabolism in this parasite, or to the nuclear localization of ROS that may limit damage to membrane-associated lipid metabolites (Gibson et al., 1999; Das et al., 2002). Moreover, protein carbonylation, an irreversible oxidative damage, showed only a tendency (not statistically significant) to increase when high $\mathrm{ABZ}$ concentrations were used, despite being easily detected when the parasites were treated with $\mathrm{H}_{2} \mathrm{O}_{2}$. Although carbonylation is an important marker for protein damage, it will also be important to analyze if other mechanisms of oxidative damage to proteins (Møller et al., 2011) may occur in the ABZ treated trophozoites.

The detection of $8 \mathrm{OHdG}$ adducts, together with DNA degradation in $\mathrm{ABZ}$ exposed trophozoites indicated that the DNA was the most affected molecule by the pro-oxidant action of ABZ. The in vitro damage of DNA by drugs such as metronidazole has been recently shown in Giardia (Uzlikova and Nohynkova, 2015). Other redox active drugs such as benzinidsazole and hydroxymethylnitrofurazone have been reported to affect mainly DNA (Davies et al., 2014), a pattern commonly present in necrosis. Further evidence of DNA damage in ABZ-treated trophozoites included histone $\mathrm{H} 2 \mathrm{AX}$ phosphorylation that indicates a repair signal after DNA double strand break. In particular, H2AX phosphorylation observed in parasites treated with $250 \mu \mathrm{M} \mathrm{ABZ}$ could be due to the cell damage induced by the drug. Thus, phosphorylation of histone H2AX will be activated upon damage of trophozoites by ABZ. As shown in Figure 7, a process of necrosis appears particularly significantly when the parasites are exposed to $250 \mu \mathrm{M}$ and in this condition $\mathrm{H} 2 \mathrm{AX}$ phosphorylation occurs.

In other parasites such as Toxoplasma gondii, the phosphorylation of H2AX has been correlated with loss of pathological potential and reduced growth rates (Vonlaufen et al., 2010). It is worth mentioning that the typical ladder pattern of DNA degradation observed in Giardia exposed to ABZ was not entirely similar to the one associated with apoptosis in other organisms or as commonly present in necrosis (Bagchi et al., 2012). Thus the DNA degradation pattern correlates with an apoptotic-like phenomenon present in G. duodenalis. Indeed, the detection of phosphatidylserine translocation to the outer side of the cell membrane suggested an apoptotic-like event.

Our findings resemble studies reported by others regarding an apoptotic-like process in Giardia when it is exposed to classical inducers of oxidative stress and to metronidazole (Bagchi et al., 2012). Interestingly a partial arrest in S and G2 phases of the cell cycle was observed in ABZ-exposed trophozoites that correlate with the induction of oxidative stress and an apoptotic-like process. It is noteworthy that the cell cycle arrest is not complete and this allows a portion of the cell population to continue through the cell cycle. The effect of different drugs on the Giardia cell cycle has been reported to show different phenomena, including partial arrest in different cell cycle stages depending on the drug under study (Reaume et al., 2013). In our work, ABZtreated trophozoites showed a pattern consistent with Giardia trophozoites displaying incomplete cytokinesis upon exposure to microtubule-acting compounds (Mariante et al., 2005).

In summary, this work demonstrated that $\mathrm{ABZ}$ induces the formation of intracellular of ROS in G. duodenalis leading to an oxidative stress status where the main affected biomolecule is DNA. This damage involves the formation of $8 \mathrm{OHdG}$ adducts and double-strand DNA break. This damage in turn leads to cell cycle dysregulation and eventually apoptotic-like cell death. These observations allow us to expand our understanding on the cytotoxic mechanism of ABZ in Giardia and opens future directions to a rational drug design for giardiasis, considering antioxidant responses as likely mechanisms of multidrug resistance. In this context, generating ROS or inhibiting endogenous antioxidant enzymes would be a rational approach to developing new anti-Giardia drugs as previously proposed for other parasites (Pal and Bandyopadhyay, 2012).

\section{Acknowledgments}

We would like to thank Dean Befus and Benjamin Rosenthal for critically reading the manuscript and for their help in reviewing the English language. Authors are grateful to José Pedraza Chaverri and Omar Medina Campos for their help in the assays for the detection of lipid peroxidation, to Blanca E. Herrera-Ramirez, Isabel Torres, Olga Garibay Cerdenares, and Viridiana Olin-Sandoval for their helpful technical assistance and to Arturo Pérez-Taylor for informatics assistance. RM-E was recipient of a doctoral fellowship from CONACYT (Reference No. 215120). This work was partially supported by Conacyt Grant No 49724-M. 


\section{References}

Ankarklev, J., Jerlström-Hultqvist, J., Ringqvist, E., Troell, K., and Svärd, S. G. (2010). Behind the smile: cell biology and disease mechanisms of Giardia species. Nat. Rev. Microbiol. 8, 413-422. doi: 10.1038/nrmicro2317

Argüello-García, R., Cruz-Soto, M., González-Trejo, R., Paz-Maldonado, L. M., Bazán-Tejeda, M. L., Mendoza-Hernández, G., et al. (2015). An antioxidant response is involved in resistance of Giardia duodenalis to albendazole. Front. Microbiol. 10:286. doi: 10.3389/fmicb.2015.00286

Argüello-García, R., Cruz-Soto, M., Romero-Montoya, L., and Ortega-Pierres, G. (2009). In vitro resistance to 5-nitroimidazoles and benzimidazoles in Giardia duodenalis: variability and variation in gene expression. Infect. Genet. Evol. 9, 1057-1064. doi: 10.1016/j.meegid.2009.05.015

Bagchi, S., Oniku, A. E., Topping, K., Mamhoud, Z. N., and Paget, T. A. (2012). Programmed cell death in Giardia. Parasitology 139, 894-903. doi: 10.1017/S003118201200011X

Bártíková, H., Vokřál, I., Skálová, L., Lamka, J., and Szotáková, B. (2010). In vitro oxidative metabolism of xenobiotics in the lancet fluke (Dicrocoelium dendriticum) and the effects of albendazole and albendazole sulphoxide ex vivo. Xenobiotica 40, 593-601. doi: 10.3109/00498254.2010.497565

Berg, M., García-Hernández, R., Cuypers, B., Vanaerschot, M., Manzano, J. I., Poveda, J. A., et al. (2015). Experimental resistance to drug combinations in Leishmania donovani: metabolic and phenotypic adaptations. Antimicrob. Agents Chemother. 59, 2242-2255. doi: 10.1128/AAC.04231-14

Chavez, B., Cedillo-Rivera, R., and Martinez-Palomo, A. (1992). Giardia lamblia: ultrastructural study of the in vitro effect of benzimidazoles. J. Protozool. 39, 510-515. doi: 10.1111/j.1550-7408.1992.tb04841.x

Das, S., Stevens, T., Castillo, C., Villasenõr, A., Arredondo, H., and Reddy, K. (2002). Lipid metabolism in mucous-dwelling amitochondriate protozoa. Int. J. Parasitol. 32, 655-675. doi: 10.1016/S0020-7519(02)00006-1

Davies, C., Dey, N., Negrette, O. S., Parada, L. A., Basombrio, M. A., and Garg, N. J. (2014). Hepatotoxicity in mice of a novel anti-parasite drug candidate hydroxymethylnitrofurazone: a comparison with Benznidazole. PLoS Negl. Trop. Dis. 8:e3231. doi: 10.1371/journal.pntd.0003231

Dayan, A. D. (2003). Albendazole, mebendazole and praziquantel. Review of non-clinical toxicity and pharmacokinetics. Acta. Trop. 86, 141-159. doi: 10.1016/S0001-706X(03)00031-7

Diawara, A., Halpenny, C. M., Churcher, T. S., Mwandawiro, C., Kihara, J., Kaplan, R. M., et al. (2013). Association between response to albendazole treatment and $\beta$-tubulin genotype frequencies in soil-transmitted helminths. PLoS Negl. Trop. Dis. 7:e2247. doi: 10.1371/journal.pntd.0002247

Dimitrijević, B., Borozan, S., Katić-Radivojević, S., and Stojanović, S. (2012). Effects of infection intensity with Strongyloides papillosus and albendazole treatment on development of oxidative/nitrosative stress in sheep. Vet. Parasitol. 186, 364-375. doi: 10.1016/j.vetpar.2011.11.017

Gardner, T. B., and Hill, D. R. (2001). Treatment of giardiasis. Clin. Microbiol. Rev. 14, 114-128. doi: 10.1128/CMR.14.1.114-128.2001

Gérard-Monnier, D., Erdelmeier, I., Régnard, K., Moze-Henry, N., Yadan, J. C., and Chaudière, J. (1998). Reactions of 1-methyl-2-phenylindole with malondialdehyde and 4-hydroxyalkenals. Analytical applications to a colorimetric assay of lipid peroxidation. Chem. Res. Toxicol. 11, 1176-1183. doi: $10.1021 /$ tx 9701790

Gerphagnon, M., Latour, D., Colombet, J., and Sime-Ngando, T. (2013). A double staining method using SYTOX green and calcofluor white for studying fungal parasites of phytoplankton. Appl. Environ. Microbiol. 79, 3943-3951. doi: 10.1128/AEM.00696-613

Ghosh, E., Ghosh, A., Ghosh, A. N., Nozaki, T., and Ganguly, S. (2009). Oxidative stress-induced cell cycle blockage and a protease-independent programmed cell death in microaerophilic Giardia lamblia. Drug. Des. Devel. Ther. 3, 103-110.

Gibson, G. R., Ramirez, D., Maier, J., Castillo, C., and Das, S. (1999). Giardia lamblia: incorporation of free and conjugated fatty acids into glycerol-based phospholipids. Exp. Parasitol. 92, 1-11. doi: 10.1006/expr.1999.4389

Hansen, T. V., Thamsborg, S. M., Olsen, A., Prichard, R. K., and Nejsum, P. (2013). Genetic variations in the beta-tubulin gene and the internal transcribed spacer 2 region of Trichuris species from man and baboons. Parasit Vectors. 6:236. doi: 10.1186/1756-3305-6-236

Hofštetrová, K., Uzlíková, M., Tůmová, P., Troell, K., Svärd, S. G., and Nohýnková, E. (2010). Giardia intestinalis: aphidicolin influence on the trophozoite cell cycle. Exp. Parasitol. 124, 159-166. doi: 10.1016/j.exppara. 2009.09.004

Keister, D. B. (1983). Axenic culture of Giardia lamblia in TYI-S-33 medium supplemented with bile. Trans. R. Soc. Trop. Med. Hyg. 77, 487-488. doi: 10.1016/0035-9203(83)90120-7

Krisko, A., and Radman, M. (2010). Protein damage and death by radiation in Escherichia coli and Deinococcus radiodurans. Proc. Natl. Acad. Sci. U.S.A. 107, 14373-14377. doi: 10.1073/pnas.1009312107

Lane, S., and Lloyd, D. (2002). Current trends in research into the waterborne parasite Giardia. Crit. Rev. Microbiol. 28, 123-147. doi: 10.1080/1040840291046713

Lehane, A. M., McDevitt, C. A., Kirk, K., and Fidock, D. A. (2012). Degrees of chloroquine resistance in Plasmodium - is the redox system involved? Int. J. Parasitol. Drugs Drug Resist. 2, 47-57. doi: 10.1016/j.ijpddr.2011.11.001

Lemée, V., Zaharia, I., Nevez, G., Rabodonirina, M., Brasseur, P., Ballet, J. J., et al. (2000). Metronidazole and albendazole susceptibility of 11 clinical isolates of Giardia duodenalis from France. J. Antimicrob. Chemother. 46, 819-821. doi: $10.1093 / \mathrm{jac} / 46.5 .819$

Li, L., and Wang, C. C. (2006). A likely molecular basis of the susceptibility of Giardia lamblia towards oxygen. Mol. Microbiol. 59, 202-211. doi: 10.1111/j.1365-2958.2005.04896.x

Locatelli, C., Pedrosa, R. C., De Bem, A. F., Creczynski-Pasa, T. B., Cordova, C. A., and Wilhelm-Filho, D. (2004). A comparative study of albendazole and mebendazole-induced, time-dependent oxidative stress. Redox. Rep. 9, 89-95. doi: 10.1179/135100004225004751

Mariante, R. M., Vancini, R. G., Melo, A. L., and Benchimol, M. (2005). Giardia lamblia: evaluation of the in vitro effects of nocodazole and colchicine on trophozoites. Exp. Parasitol. 110, 62-72. doi: 10.1016/j.exppara.2005.01.007

Mastronicola, D., Falabella, M., Testa, F., Pucillo, L. P., Teixeira, M., Sarti, P., et al. (2014). Functional characterization of peroxiredoxins from the human protozoan parasite Giardia intestinalis. PLoS Negl. Trop. Dis. 8:e2631. doi: 10.1371/journal.pntd.0002631

Møller, I. M., Rogowska-Wrzesinska, A., and Rao, R. S. (2011). Protein carbonylation and metal-catalyzed protein oxidation in a cellular perspective. J. Proteomics. 74, 2228-2242. doi: 10.1016/j.jprot.2011.05.004

Moore, C. J., Shao, C. H., Nagai, R., Kutty, S., Singh, J., and Bidasee, K. R. (2013). Malondialdehyde and 4-hydroxynonenal adducts are not formed on cardiac ryanodine receptor (RyR2) and sarco(endo)plasmic reticulum Ca2+-ATPase (SERCA2) in diabetes. Mol. Cell. Biochem. 376, 121-135. doi: 10.1007/s11010013-1558-1

Müller, J., Sterk, M., Hemphill, A., and Müller, N. (2007). Characterization of Giardia lamblia WB C6 clones resistant to nitazoxanide and to metronidazole. J. Antimicrob. Chemother. 60, 280-287. doi: 10.1093/jac/dkm205

Nandi, M., and Sarkar, S. (2013). Albendazole-induced recurrent hepatitis. Indian Pediatr. 50, 1064. doi: 10.1007/s13312-013-0285-8

Nash, T. E. (2013). Unraveling how Giardia infections cause disease. J. Clin. Invest. 123, 2346-2347. doi: 10.1172/JCI69956

Orozco-Ibarra, M., Medina-Campos, O. N., Sánchez-González, D. J., MartínezMartínez, C. M., Floriano-Sánchez, E., Santamaría, A., et al. (2007). Evaluation of oxidative stress in D-serine induced nephrotoxicity. Toxicology 229, 123-135. doi: 10.1016/j.tox.2006.10.008

Oxberry, M. E., Reynoldson, J. A., and Thompson, R. C. (2000). The binding and distribution of albendazole and its principal metabolites in Giardia duodenalis. J. Vet. Pharmacol. Ther. 23, 113-120. doi: 10.1046/j.1365-2885.2000.00254.x

Pal, C., and Bandyopadhyay, U. (2012). Redox-active antiparasitic drugs. Antioxid. Redox. Signal. 17, 555-582. doi: 10.1089/ars.2011.4436

Pal, D., Banerjee, S., Cui, J., Schwartz, A., Ghosh, S. K., and Samuelson, J. (2009). Giardia, Entamoeba, and Trichomonas enzymes activate metronidazole (nitroreductases) and inactivate metronidazole (nitroimidazole reductases). Antimicrob. Agents Chemother. 53, 458-464. doi: 10.1128/AAC. 00909-08

Paz-Maldonado, M. T., Argüello-García, R., Cruz-Soto, M., MendozaHernández, G., and Ortega-Pierres, G. (2013). Proteomic and transcriptional analyses of genes differentially expressed in Giardia duodenalis clones resistant to albendazole. Infect. Genet. Evol. 15, 10-17. doi: 10.1016/j.meegid.2012.08.021

Plutzer, J., Ongerth, J., and Karanis, P. (2010). Giardia taxonomy, phylogeny and epidemiology: facts and open questions. Int. J. Hyg. Environ. Health. 213, 321-333. doi: 10.1016/j.ijheh.2010.06.005 
Poole, K. (2014). Stress responses as determinants of antimicrobial resistance in Pseudomonas aeruginosa: multidrug efflux and more. Can. J. Microbiol. 60, 783-791. doi: 10.1139/cjm-2014-2666

Raj, D., Ghosh, E., Mukherjee, A. K., Nozaki, T., and Ganguly, S. (2013). Differential gene expression in Giardia lamblia under oxidative stress: significance in eukaryotic evolution. Gene. 535, 131-139. doi: 10.1016/j.gene.2013.11.048

Reaume, C., Moore, B., Hernández, P., Ruzzini, A., Chlebus, M., Wasserman, M., et al. (2013). Evaluation of drugs and stationary growth on the cell cycle of Giardia intestinalis. Mol. Biochem. Parasitol. 187, 72-76. doi: 10.1016/j.molbiopara.2012.11.005

Robinson, M. W., McFerran, N., Trudgett, A., Hoey, L., and Fairweather, I. (2004). A possible model of benzimidazole binding to beta-tubulin disclosed by invoking an inter-domain movement. J. Mol. Graph. Model. 23, 275-284. doi: 10.1016/j.jmgm.2004.08.001

Rossignol, J. F. (2010). Cryptosporidium and Giardia: treatment options and prospects for new drugs. Exp. Parasitol. 124, 45-53. doi: 10.1016/j.exppara.2009.07.005

Rossignol, J. F., Lopez-Chegne, N., Julcamoro, L. M., Carrion, M. E., and Bardin, M. C. (2012). Nitazoxanide for the empiric treatment of pediatric infectious diarrhea. Trans. R. Soc. Trop. Med. Hyg. 106, 167-173. doi: 10.1016/j.trstmh.2011.11.007

Solaymani-Mohammadi, S., Genkinger, J. M., Loffredo, C. A., and Singer, S. M. (2010). A meta-analysis of the effectiveness of albendazole compared with metronidazole as treatments for infections with Giardia duodenalis. PLoS Negl. Trop. Dis. 4:e682. doi: 10.1371/journal.pntd.0000682

Suzuki, K., Ojima, M., Kodama, S., and Watanabe, M. (2006). Delayed activation of DNA damage checkpoint and radiation-induced genomic instability. Mutat. Res. 597, 73-77. doi: 10.1016/j.mrfmmm.2005.04.024

Tejman-Yarden, N., and Eckmann, L. (2011). New approaches to the treatment of giardiasis. Curr. Opin. Infect. Dis. 24, 451-456. doi: 10.1097/QCO.0b013e32834ad401
Tian, H. F., Chen, B., and Wen, J. F. (2010). Giardiasis, drug resistance, and new target discovery. Infect. Disord. Drug Targets. 10, 295-302. doi: $10.2174 / 187152610791591629$

Upcroft, J., Mitchell, R., Chen, N., and Upcroft, P. (1996). Albendazole resistance in Giardia is correlated with cytoskeletal changes but not with a mutation at amino acid 200 in beta-tubulin. Microb. Drug Resist. 2, 303-308. doi: 10.1089/mdr.1996.2.303

Upcroft, P., and Upcroft, J. A. (2001). Drug targets and mechanisms of resistance in the anaerobic protozoa. Clin. Microbiol. Rev. 14, 150-164. doi: 10.1128/CMR.14.1.150-164.2001

Uzlikova, M., and Nohynkova, E. (2015). The effect of metronidazole on the cell cycle and DNA inmetronidazole-susceptible and -resistant Giardia cell lines. Mol. Biochem. Parasitol. 198, 75-81. doi: 10.1016/j.molbiopara.2015.01.005

Vonlaufen, N., Naguleswaran, A., Coppens, I., and Sullivan, W. J. Jr. (2010). MYST family lysine acetyltransferase facilitates ataxia telangiectasia mutated (ATM) kinase-mediated DNA damage response in Toxoplasma gondii. J. Biol. Chem. 285, 11154-11161. doi: 10.1074/jbc.M109.066134

Watkins, R. R., and Eckmann, L. (2014). Treatment of giardiasis: current status and future directions. Curr. Infect. Dis. Rep. 16, 396. doi: 10.1007/s11908-014 0396-y

Conflict of Interest Statement: The authors declare that the research was conducted in the absence of any commercial or financial relationships that could be construed as a potential conflict of interest.

Copyright (C) 2015 Martínez-Espinosa, Argüello-García, Saavedra and Ortega-Pierres. This is an open-access article distributed under the terms of the Creative Commons Attribution License (CC BY). The use, distribution or reproduction in other forums is permitted, provided the original author(s) or licensor are credited and that the original publication in this journal is cited, in accordance with accepted academic practice. No use, distribution or reproduction is permitted which does not comply with these terms. 